\title{
Código de Defesa do Consumidor: o direito do cidadâo alicerçado na informação
}

Consumer Protection Code: citizens' rights grounded on information

Código de Defensa del Consumidor: el derecho del ciudadano fundado en la información

Denize Aparecida Guazzelli

- Mestre em Comunicação Social e graduada em Relações Públicas pela Universidade Metodista de São Paulo (Umesp)

- Docente dos cursos de Relações Públicas da da Umesp, de 1990 a 2009, e das Faculdades Integradas Alcântara Machado (Fiam), de 1996 a 1999

- É assessora de relações públicas e ouvidora da Fundação Sistema Estadual de Análise de Dados (Fundação Seade), de São Paulo

- Atuou por mais de vinte anos como relações-públicas em organizações privadas nacionais e multinacionais

- Publicou os artigos "Relações públicas em defesa do consumidor" e "Relações públicas e ombudsman: relacionamento 2.0"

-denize@jjcarreau.com; guazzelli@seade.gov.br 
Resumo

Destacar o Código de Defesa do Consumidor (CDC) sob o prisma de sua motivação informativa e conscientizadora, estabelecendo paralelos com o instituto da ouvidoria e dos demais organismos e instrumentos que cumprem relevante papel na consolidação dos direitos conquistados pelos cidadãos e no estabelecimento de novos parâmetros nas relações de consumo é o propósito do presente artigo.

PALAVRAS-CHAVE: CIDADANIA • DIREITOS DO CONSUMIDOR • INFORMAÇÃO • OUVIDORIA • RELAÇÕES DE CONSUMO

Abstract

The proposition of this article is of stressing the Brazilian Consumer Protection Code, from the aspect by which it provides motivation and awareness, establishing comparisons with the doctrine of listening and with all of the other instruments that play relevant roles for consolidation of citizens' rights and for establishment of new parameters for consumer relations.

KEYWORDS: CITIZENSHIP • CONSUMER RIGHTS • INFORMATION • LISTENER'S OFFICE • OMBUDSMAN • CONSUMER RELATIONS

\section{Resumen}

El propósito del presente artículo es destacar el Código de Defensa del Consumidor (CDC) del Brasil bajo el prisma de su motivación de informar y concienciar, al tiempo que se establecen paralelos con el instituto de la defensoría y los demás organismos e instrumentos que cumplen un papel relevante para la consolidación de los derechos conquistados por los ciudadanos y el establecimiento de nuevos parámetros en las relaciones de consumo.

PALAVRAS CLAVE: CIUdAdANÍA • DERECHOS DEL CONSUMIDOR • INFORMACIÓN • DEFENSORÍA • RELACIONES DE CONSUMO 
$\mathrm{N}$ as últimas décadas, os direitos conquistados pelos cidadãos, originariamente os civis e os políticos, têm sido ampliados e complementados por direitos sociais. "Esses vários direitos, garantias e proteções vêm se constituindo como pilares do capitalismo social e, em seu âmago, revelam um sentido ético, pois conferem à responsabilidade social e ao altruísmo um papel relevante na convivência coletiva" (SROUR, 2000, p. 196-197).

É nesse ambiente que se insere o Código de Defesa do Consumidor (CDC) - Lei n.8.078/90 -, que, completando vinte anos agora em $2010^{1}$, tem base no art. $5^{\circ}$, inciso XXXII, da Constituição da República Federativa do Brasil, no qual se estabelece que "o Estado promoverá, na forma da lei, a defesa do consumidor"2.

A defesa do consumidor, na forma de lei, foi, dessa forma, prevista na atual Constituição, aclamada pelo deputado Ulisses Guimarães, presidente da Assembleia Nacional Constituinte, no ato de sua promulgação, em 1988, como a "Constituição cidadã”. Segundo Cândido Teobaldo de Souza Andrade (2003, p. 24),

a fórmula tinha finalidade clara: indicar não só que essa era uma Lei Magna nascida dos anseios manifestados, direta e indiretamente, pela cidadania, como também, e acima disso, uma constituição que assegura ao cidadão - e o conclama a isso - a fiscalização (pari passu) e a correção da atividade administrativa.

De acordo com Andrade (2003, s. p.), cidadania é um tema contemporâneo que enseja diversos ângulos de análise, mas que sempre refletem "manifestações sociais típicas de ambientes de relacionamento, os quais precisam das atividades de relações públicas para atingir os seus objetivos"

O mesmo fator condicionante está arrolado no Código de Defesa do Consumidor. Em vez de apenas ditar regras e sanções, logo no início de seu enunciado, tal como um guia de boas práticas, o código preconiza a harmonização dos interesses dos participantes nas relações de consumo, com base no equilíbrio dessas relações e, entre outros princípios, alerta para a necessidade de promover a educação e informação de fornecedores e consumidores, quanto aos seus direitos e deveres, com vistas à melhoria do mercado de consumo.

É com base nesse eixo que se desenvolve o presente artigo, buscando, em uma breve recuperação histórica do consumerismo e nas articulações do CDC com os demais agentes, pontuar essa nova fase nas relações de consumo, que privilegia a informação como meio de inserção participativa do cidadão nesse contexto. Além da proteção os seus direitos, o cidadão deve ser atendido (também como um direito) nas suas necessidades de informação e de orientação (pré e pós-venda), bem como contar com quem o represente e possa atuar na mediação de conflitos oriundos dos chamados 'acidentes' de consumo.

1 A lei, assinada em 11 de setembro de 1990, entrou em vigor em 11 de março de 1991.

2 Cf.: <https://www.planalto.gov.br/>. 
Tais aspectos, em destaque na lei, estão presentes na concepção contemporânea que atribui às relações públicas a função de gestora de relacionamentos, buscando o equilíbrio entre as partes envolvidas. Para Ferrari (2006, p. 87), a atividade é responsável por "administrar os relacionamentos de uma organização com seus públicos, com o objetivo de manter um diálogo duradouro e eficaz, que permita a possibilidade de simetria entre ambos os protagonistas de uma determinada ação". No âmbito da prática de "relações públicas excelentes", Grunig e Hunt (1984), ao propor o modelo simétrico de duas mãos, postulam que a atividade deve servir ao equilíbrio dos interesses da organização e os de seus públicos, por meio do uso planejado das ferramentas da comunicação, para administrar conflitos. Da parte das instituições, consideramos, portanto que tais pressupostos constituem uma premissa básica da legitimação de suas ações.

Porto Simões (1995) destaca como essencial a função política de relações públicas. Para o autor, ao administrar relacionamentos no âmbito das organizações, as relações públicas lidam diretamente com as relações de poder e, ao gerir tais relações, desenvolvem a função política da atividade. Transpondo o conceito para o âmbito da lei aqui discutida, tocamos em um dos pontos fortes do CDC: a proteção ao lado mais fraco na relação - o consumidor, aspecto que nos remete a outro importante papel desempenhado pelo código: o de catalisador da prática da responsabilidade social empresarial.

Desse modo, no desenvolvimento de nossa análise sobre os impactos do CDC e também sobre o papel do instituto da ouvidoria, vamos nos deparar, ainda, com outras intersecções entre os princípios desses e os princípios das relações públicas defendidos por estudiosos que se dedicam à consolidação de uma teoria geral de relações públicas.

\section{DOS MOVIMENTOS CONSUMERISTAS AO CDC}

O termo consumerismo foi introduzido nos Estados Unidos na década de 1960 para designar movimentos organizados de cidadãos na defesa de seus direitos contra abusos praticados pelas empresas. Algumas definições da expressão incluem também movimentos de governos com o mesmo propósito. Para Giacomini Filho (1991, p. 19), "são formas agentes e pacientes do consumerismo: consumidores, produtores, comerciantes e instituições públicas e privadas (grifo nosso), enfim, qualquer elemento nas relações de consumo que repercuta na compra, usufruto e consumo de algo".

A introdução do termo consumerismo é recente. No entanto, as primeiras manifestações ${ }^{3}$ de cidadãos para definir e fazer valer seus direitos, naquele país,

3 New York Consumers League, 1891: criada para melhorar as condições de trabalho dos empregados do comércio; National Consumers League (NCL), 1899: a exemplo dos atuais movimentos preservacionistas, orientava consumidores a adquirir apenas produtos que ostentassem um selo que atestava a utilização de métodos de trabalho que respeitavam o trabalhador (ZÜLZKE, 1990, p. 8). 
datam do século XIX e prosseguem pelo século seguinte, provocando acontecimentos determinantes rumo ao reconhecimento desses direitos.

Já por volta de 1905, a opinião pública estava revoltada com a ocorrência de irregularidades na indústria da carne e na indústria de medicamentos, fatos que eram divulgados pela imprensa. Foi nessa época que o jornalista Ivy Lee introduziu na América do Norte uma nova profissão: as relações públicas. John D. Rockefeller, então o homem mais impopular dos Estados Unidos, contratou os serviços do jornalista para reverter sua imagem negativa - o que foi conseguido graças a investimentos do magnata em ações de cunho social e aos esforços para a ampla divulgação pública de tais iniciativas (OLIVEIRA, 1971).

O pioneirismo americano na luta pela defesa dos direitos do consumidor avançou pelas décadas seguintes, culminando, em 1962, com o envio da mensagem do presidente John F. Kennedy ao Congresso Norte-Americano, o qual instituiu os quatro direitos fundamentais do consumidor: direito à segurança, direto à informação, direito à escolha e direito a ser ouvido.

Em 1985, a Organização das Nações Unidas (ONU) define as diretrizes de defesa do consumidor, adicionando mais quatro direitos àqueles propostos por Kennedy: direito ao ressarcimento, direito à educação para o consumo (grifo nosso), direito a um meio ambiente saudável e direito ao acesso a bens e serviços.

Antes ainda, na década de 1940, após o término da II Guerra Mundial, os movimentos de consumidores já começavam a emergir pelo mundo afora, sobretudo em países da Europa, além de Austrália, Canadá e Japão. Era o início da internacionalização da economia e das fusões empresariais, talvez um dos primeiros indícios do fenômeno da globalização. Fato consumado algumas décadas depois - em ambiente democrático -, a globalização, veio compor com o desenvolvimento e a popularização dos recursos tecnológicos (que eliminaram as distâncias geográficas) o contexto propício, também, para a difusão em cadeia transnacional dos movimentos ativistas. Estes deixavam de ter aquele caráter exclusivamente revolucionário e radical para assumir um novo perfil, com o surgimento de organizações não-governamentais (ONGs) e grupos de pressão organizados em rede, os quais lutam pelas mais diversas causas: de minorias (como as mulheres), ambientalistas e por direitos civis (MACHADO, 2007).

No Brasil, embora sem a mesma intensidade, os movimentos consumeristas inscreveram sua relevância ao refletir a conscientização dos cidadãos sobre seus direitos e a luta por uma relação menos desigual entre vendedores (ou aqueles que fabricam e distribuem) e compradores, tanto no âmbito público como no privado. Segundo Taschner (2009, p. 167), "é preciso dizer que a questão da defesa do consumidor chegou ao Brasil, irradiada dos Estados Unidos, mas atrasada em relação à Europa: ela aportou aqui no início dos anos 1970”. O que antes existia era alguma legislação para protegê-lo e nada mais. 
A sociedade brasileira ainda está amadurecendo conceitos como direito e cidadania. Os primeiros movimentos consumeristas, em nosso País, relacionados à carestia, ocorreram entre as décadas de 1930 e de 1960.

Entre as décadas de 1960 e 1970, vivemos o singular período do "milagre" brasileiro. Enquanto os países industrializados já estavam atentos à destruição e ao desperdício dos recursos naturais não-renováveis, o Brasil vivia um clima de euforia, balizado por um desordenado crescimento econômico, no qual não havia espaço para questões relacionadas ao meio ambiente e aos direitos do consumidor.

Na década seguinte, não por acaso, começaram a surgir associações de consumidores e entidades civis de defesa do consumidor. No meio empresarial, a reação foi mais lenta. Até então, o ambiente ainda era confortável para as empresas que não sofriam pressões dos consumidores. Até a década de 1980, poucas haviam se movimentado no sentido de estabelecer políticas de relacionamento com o consumidor ou de criar canais de comunicação, que balizassem a prática de princípios básicos para manter uma relação harmoniosa com esse que constitui um dos públicos de sustentação da organização, imprescindível à sua viabilização e, sobretudo, nesse caso, à sua manutenção no mercado (FRANÇA, 2004). E, mesmo entre as empresas que declaravam praticar relações públicas, prevalecia o culto à prática do modelo de 'agência de imprensa/divulgação’, com o objetivo primordial de atender a propósitos promocionais (GRUNIG, 2009).

O contraponto, ao menos no aspecto formal, era a proliferação de leis e outras iniciativas governamentais. Já no Código Comercial de 1850 encontrava-se o seguinte artigo: "O vendedor, ainda depois da entrega, fica responsável pelos vícios e defeitos na coisa vendida, que o comprador não podia descobrir antes de recebê-la” (GIACOMINI, 1991, p. 27).

A presença do agente estatal é uma constante que pode ser verificada, ao se recuperarem, mesmo que minimamente, fatos da história recente do consumerismo em nosso País. Em 1982, antes, portanto, da promulgação do Código de Defesa do Consumidor, Luiz Amaral (1991) reuniu, na obra denominada Relações de consumo, mais de mil atos normativos, leis, decretos e portarias, concluindo que, se dependesse de leis, o consumidor brasileiro seria o mais protegido do mundo.

No entanto, não basta apenas a lei estar formalizada e promulgada. Como afirma o economista Eduardo Giannetti (1993, p.153),

uma constituição política perfeita promulgada para cidadãos despreparados e apáticos vale tanto quanto uma obra de Machado de Assis nas mãos de um analfabeto. O mesmo se aplica para a constituição econômica. As regras do jogo econômico - sejam elas quais forem e por mais brilhantes que sejam - não 
são capazes de produzir resultados satisfatórios caso os jogadores não possuam os atributos cognitivos e morais necessários para tirar delas bom proveito.

Nesse aspecto, o CDC é proativo, ao apontar a necessidade de se promover a educação de todos os atores que participam das relações de consumo, para formar a consciência cidadã. Ao entrar em vigor, o código referendou os esforços que vinham sendo empreendidos pelas nascentes organizações civis e governamentais de proteção ao consumidor. Entre essas, destaca-se a criação do Sistema Estadual de Defesa do Consumidor, nos estados de São Paulo e do Rio Grande do Sul, batizado como Procon, no ano 1976.

Hoje, os Procons integram o Sistema Nacional de Defesa do Consumidor (SNDC). São órgãos estaduais (27 no total - um para cada unidade da Federação e o Distrito Federal) e municipais de defesa do consumidor, criados, na forma da lei, especificamente para esse fim, com competências, no âmbito de sua jurisdição, para exercitar as atividades contidas no CDC.

Como ouvidorias públicas, os Procons desempenham o papel de educar e conscientizar a população consumidora, por meio de esclarecimentos, via consulta, elaboração e distribuição de cartilhas e manuais, divulgação de pesquisas de preços e de orientação pela imprensa, além da criação de canais para informações sobre empresas que constam do cadastro da instituição e que são alvo de reclamações recorrentes. É um tipo de "SPC das empresas". Só que, nesse caso, a inadimplência é de ordem moral.

Na virada para o século XXI, Taschner (2009, p. 159) observa que começou a esboçar-se com mais clareza uma nova fronteira de atuação política do consumidor, quando este

aprofundou a consciência de seu poder econômico e político e passou a lutar por causas que transcendiam seus interesses específicos. Os boicotes a empresas que não têm 'boas práticas' (uso do trabalho infantil, de produtos agressivos ao ambiente, crueldade com animais), além do uso da mídia, tornaram os consumidores atores políticos nada desprezíveis.

\section{CÓDIGO BRASILEIRO DE DEFESA DO CONSUMIDOR: EM SINTONIA COM A SOCIEDADE}

Com o caminho aberto pela ação precursora das instituições de defesa do consumidor, a lei obteve uma acolhida social que poucas iniciativas lograram e conseguiu promover, de modo eficiente, a conscientização da população sobre o valor de sua participação como agente de mudança no desenvolvimento social, de garantia de seus direitos e, principalmente, da sua força como agente de uma relação jurídica de consumo. "O Código de Defesa do Consumidor fomentou o nascimento e desenvolvimento de inúmeras associações que, com 
sua atuação na defesa dos interesses dos consumidores brasileiros, aperfeiçoaram a aplicação dessa nova disciplina legislativa”, afirmou a ministra do Superior Tribunal de Justiça, Fátima Nancy Andrighi (2009).

Pela imprensa - setor que tem papel essencial na disseminação da informação como instrumento de conscientização da sociedade - o CDC foi recebido como um vigoroso estímulo à prática de uma cidadania mais participativa e saudado por transcender o aspecto legal, constituindo um manual de boas práticas que reflete o novo status do consumidor, que está mais exigente, consciente, maduro e esclarecido (MEIR, 2009).

Além do noticiário e de reportagens sobre o tema, antes do CDC, inúmeros veículos da imprensa escrita criaram colunas para publicar reclamações de consumidores, igualmente abertas às empresas para responder às queixas e denúncias.

Já a menção ao manual de boas práticas nos remete aos códigos de conduta ou códigos de ética, que se tornaram um recurso comum utilizado pelas empresas com o intuito de aperfeiçoar os relacionamentos internos e externos de uma organização e elevar o clima de confiança nela existente e manter-se em sintonia com as expectativas da sociedade ${ }^{4}$.

\section{Educação e informação}

A lei reconheceu e detalhou os direitos básicos do consumidor; criou normas específicas para a responsabilidade civil do fornecedor pela impropriedade de serviços e produtos comercializados; possibilitou a inversão do ônus da pro$\mathrm{va}^{5}$, que passou a ser exigido do fornecedor e não mais do consumidor; dispôs sobre a publicidade e a propaganda, criando os conceitos de abusiva e/ou enganosa; estabeleceu mecanismos para o controle das condições gerais dos contratos em geral e dos contratos de adesão; instituiu instrumentos para serem utilizados pelo consumidor para sua autodefesa; e dispôs sobre o aparato repressivo administrativo e penal, estabelecendo, assim, novas prerrogativas ao consumidor (ZÜLZKE, 1990, p. 43).

Vale ressaltar que o consumidor, conforme entendido pelo CDC, é toda pessoa física ou jurídica que adquire ou utiliza produto ou serviço como destinatário final. O importante para o CDC é que o adquirente do produto ou serviço faça a aquisição com o fim de consumo próprio. O intermediário na relação de consumo não é considerado consumidor e não tem a proteção do

4 Fonte: Código de Ética da empresa Aracruz Celulose. Disponível em: <http://www.aracruz.com.br/show_ inv.do? orig $=$ fin\&menu $=$ true\&id $=59$ \&lastRoot $=30$ \&act $=$ stcNews\&lang $=1 \#$ int $>$.

5 Ônus da prova significa que, diante da autoridade, a pessoa que alega alguma coisa tem a obrigação ou 0 ônus de provar o que está falando. 0 CDC introduziu a inversão do ônus da prova. A obrigação de provar, na maioria das vezes, não é de quem alega, no caso o consumidor, mas, sim, da parte contrária, o fornecedor. 
CDC. A relação de intermediação, distribuição, comercialização e produção é regida pelo direito comum.

Por essa razão, a filosofia do CDC é protecionista, pois considera que uma das partes na relação de consumo é, por natureza, mais fraca, uma vez que não possui o grau de conhecimento sobre os produtos e serviços da mesma forma e profundidade que o produtor ou fornecedor, como também não dispõe dos recursos para possuí-lo ou exigi-lo.

Entre os mencionados direitos básicos, o código estabeleceu "o direito à educação e divulgação sobre o consumo adequado dos produtos e serviços, asseguradas a liberdade de escolha e a igualdade nas contratações.” Portanto, a informação passou a ser uma qualidade inerente ao produto e ao serviço, sem a qual estes não podem circular no mercado.

A informação deve ser verdadeira, até mesmo na publicidade que se faça do produto. O CDC define que o consumidor deve, fácil e imediatamente, identificá-la como tal. É considerada enganosa a publicidade capaz de induzir o consumidor a erro.

Outra exigência importante é que o consumidor seja informado sobre seus direitos de forma inequívoca, adequada, precisa, clara e ostensiva. Informação, aliás, é uma das mais fortes tônicas do CDC-está presente em 29 de seus 108 artigos.

Por ocasião da entrada em vigor da lei, os empresários brasileiros sentiramse ameaçados pelo seu teor protecionista. Muitos a consideravam estimuladora de ações oportunistas ou de má-fé por parte dos consumidores. Porém, o caos tão temido não ocorreu. O espírito da lei não é repressivo e sim preventivo, no sentido de incentivar os fornecedores a cumprir as regras que lhes cabem e oferecer aos consumidores produtos e serviços de qualidade, sem riscos à sua saúde e segurança. O sentido prevencionista do CDC tem um valor agregado: "o respeito à inteligência e à dignidade do consumidor, assegurando seu direito à avaliação crítica e livre escolha dos produtos e serviços oferecidos no mercado" (NUNES, 1992, p. 2).

Todos esses aspectos remetem, naturalmente, a outro atributo (não declarado) considerado fundamental pela lei no âmbito dos direitos do consumidor: o direito à qualidade no atendimento prestado pelo fornecedor. Cortesia, atenção, respeito e celeridade são alguns dos atributos essenciais ao bom atendimento. No entanto, segundo Las Casas (2006, p. 16), cada cliente cria expectativas próprias a respeito do atendimento ou do serviço, razão pela qual é preciso conhecer tais expectativas para atendê-las da melhor forma possível, criando, assim, na mente do cliente a concepção de qualidade do serviço ou do atendimento prestado: "o produto final de um serviço é sempre um sentimento. Os clientes/ usuários ficam satisfeitos ou não conforme suas expectativas”. 
O CDC tem demonstrado que é possível o entendimento e a sua aplicabilidade de forma preventiva. Além de sua finalidade precípua, de defesa dos direitos do consumidor brasileiro, o código vem cumprindo um papel catalisador na ampliação das fronteiras do conhecimento do cidadão sobre seus direitos. Ele motivou (e continua a motivar) uma série de ações que ampliaram a sua disseminação nos meios de comunicação de massa - hoje, sobretudo na internet -, promoveram sua distribuição na forma de cartilhas e de fôlderes por entidades de defesa do consumidor e também por empresas, em iniciativas que muito contribuíram para a popularização da lei.

É voz corrente entre juristas, advogados e magistrados que o CDC representou um significativo avanço, alinhando o Brasil aos demais países desenvolvidos que, ao longo do século XX, se curvaram à necessidade de interferir efetivamente nos, até então, blindados "princípios" do livre mercado, orientados pela "lei" da oferta e da procura.

Uma das virtudes dessa lei é a de se manter atual, conforme atestou Maria Inês Fornazaro (1999, s. p. $)^{6}$, em publicação do CDC pelo Procon-SP:

Outra qualidade que essa lei vem demonstrando é a sua versatilidade, uma vez que após quase uma década e inúmeras modificações no mercado de consumo (internet, telefonia celular etc.), o Código de Defesa do Consumidor continua mantendo sua atualidade jurídica, já que os legisladores quando de sua redação tomaram cuidado para estipular dispositivos genéricos, evitando assim restringir a sua aplicação.

O código serviu de exemplo para várias outras leis e, em alguns pontos, é mais avançado do que a legislação de países de primeiro mundo. No entanto, mais importante do que a notoriedade alcançada é o fato de a lei ter resultado da pressão da sociedade organizada na defesa de seus direitos, por meio de grupos ativistas, unindo cidadãos em torno de causas e ideologias comuns, muitas delas institucionalizadas em ONGs.

Tais grupos, também denominados públicos estratégicos, são objeto das relações públicas, uma vez que Simões (1995) afirma que o objeto central da atividade são os públicos. Sob esse enfoque, Grunig (2009, p. 43) nos traz um sólido reforço, ao afirmar que, se a organização ignora ou se opõe aos interesses dos públicos, "estes se organizam em grupos ativistas para confrontar e desafiar a organização. O resultado é o conflito. Relações públicas servem à sociedade trabalhando com públicos para resolver os conflitos que a dividem”.

Kunsch (2003), com base em resolução com a definição das funções de relações públicas publicada pelo Conselho Federal de Profissionais de Relações Públicas (Conferp) em 1997, evoca o papel social da atividade, ao apontar en-

6 À época, Maria Inês Fornazaro era diretora executiva do Procon-SP. 
tre suas práticas, o planejamento, a coordenação e a execução de programas de interesse comunitário, de informação para a opinião pública, de comunicação dirigida, da utilização de tecnologia de informação aplicada à opinião pública e de esclarecimento de grupos, autoridades e opinião pública sobre os interesses da organização.

As áreas de atendimento (SACs), mas sobretudo as ouvidorias, por representarem o consumidor, podem ser mais do que uma "caixa de reclamações", transformando o serviço em um canal privilegiado de interlocução e de aferição constante da satisfação do consumidor. Isso nos remete à convergência com uma das expertises das relações públicas: a realização de pesquisas institucionais, ferramenta essencial ao planejamento de relações públicas e da comunicação organizacional. Com isso, verifica-se que relações públicas e ouvidoria transitam sobre a mesma plataforma de princípios.

\section{Sistema Nacional de Defesa do Consumidor: 0 código na prática}

Criado por decreto federal, o Sistema Nacional de Defesa do Consumidor (SNDC) estabelece as normas gerais de aplicação das sanções administrativas previstas no CDC. Dele fazem parte a Secretaria de Direito Econômico (SDE) do Ministério da Justiça, por meio do seu Departamento de Proteção e Defesa do Consumidor (DPDC), e os demais órgãos federais, estaduais, do Distrito Federal, municipais e as entidades civis de defesa do consumidor, como o Instituto Brasileiro de Defesa do Consumidor (Idec) e inúmeras associações constituídas por cidadãos, a exemplo dos pioneiros Movimento das Donas de Casa e Consumidores de Minas Gerais (MDC/MG) e Movimento de Donas de Casa e Consumidores do Rio Grande do Sul, (MDCC/ $\mathrm{RS}$ ), na década de $1980^{7}$. Ou seja, o sistema reconhece e incorpora grupos e organizações ativistas da sociedade civil.

\section{0 paradoxo do SAC}

Os Serviços de Atendimentos a Consumidores (SACs), que tiveram crescimento exponencial por ocasião da entrada em vigor do CDC, tornaram-se, eles mesmos, os principais alvos de reiteradas reclamações apresentadas a órgãos de defesa dos consumidores por culpa da fragilidade do serviço prestado, que atingiu proporções massivas, haja vista o crescente universo de usuários, nas áreas de telecomunicações e nos sistemas financeiro e de transporte aéreo.

A percepção das empresas desses setores quanto à necessidade de definir parâmetros de autorregulamentação em seus segmentos de atuação, de forma a

\footnotetext{
7 Cf. $<$ http://portal.mj.gov.br>.
} 
consolidar e aprimorar o atendimento aos consumidores, levou as entidades ${ }^{8}$ que representam o mercado de relacionamento a criarem, em 2005, o Programa Brasileiro de Auto-Regulamentação (Probare) ${ }^{9}$, composto por quatro elementos: código de ética; ouvidoria; selo de ética; e norma de maturidade de gestão.

No entanto, a manutenção da elevada incidência de queixas sobre o atendimento levou o Ministério da Justiça, por meio de seu Sistema Nacional de Defesa do Consumidor (SNDC), a estabelecer regras para o funcionamento do SAC, para obrigar as empresas a cumprirem o código, no que este se refere aos mecanismos de atendimento ao consumidor. A iniciativa, que recebeu o rótulo de "Lei do SAC" é na verdade o Decreto Federal n. 6.523/2008 ${ }^{10}$.

Segundo Ricardo Morishita, Diretor do Departamento de Proteção e Defesa do Consumidor (DPDC), do Ministério da Justiça, o código estabelece as diretrizes gerais, as finalidades e o conceito do atendimento, "mas o que se notava é que esse conceito não vinha sendo cumprido, no dia a dia” (ALCALDE, 2008).

O objetivo da regulamentação trazida com o decreto é garantir a observância dos direitos básicos do consumidor, sobretudo daquele a que temos nos referido com tanta ênfase: o direito à informação, um dos pilares que sustenta os direitos dos consumidores. "É um decreto que, em um mundo ideal, no qual as empresas espontaneamente respeitassem as regras previstas em uma lei federal como é o Código de Defesa do Consumidor, não precisaria existir”, afirma Estela Guerrini (2009), advogada do Idec.

Vale ressaltar a importância do atendimento como fator integrante da postura empresarial. Por mais grave que seja o problema, pior é não reconhecê-lo e não se esforçar para apresentar a solução ao demandante.

\section{OUVIDORIA/OMBUDSMAN: 0 FIEL DA BALANÇA}

"O cidadão e a garantia dos seus direitos só tem significado concreto em um estado democrático de direito, por consequência, unicamente em uma democracia o ouvidor/ombudsman pode existir" (VISMONA, 2005). Talvez isso explique por que, no Brasil, o primeiro registro de atuação de um "representante do consumidor" - ombudsman - dentro de uma empresa e por ela designado, ocorreu apenas em 1985 , por iniciativa da Rhodia ${ }^{11}$. Na im-

8 Associação Brasileira de Marketing Direto (Abemd), Associação Brasileira das Relações Empresa Cliente (Abrarec) e Associação Brasileira de Telesserviços (ABT).

9 Cf.: $<$ http://www.probare.com.b $>$.

10 Cf.: <http://www.planalto.gov.b>.

110 setor foi chamado de Núcleo de Valorização do Consumidor. Antes, em 1981, a Rhodia promoveu uma campanha publicitária que estimulava o consumidor a estabelecer contato com a empresa, utilizando o slogan: "Você fala, a Rhodia escuta." (VALENTE; NORI, 1990, p. 50). 
prensa, o jornal Folha de S.Paulo instituiu o ombudsman do leitor, o primeiro da imprensa brasileira, em 1989.

Com a missão de defender o cidadão, o correspondente na administração pública se deu com a instituição da primeira ouvidoria municipal, na cidade de Curitiba (PR), em 1986.

Segundo Edson Vismona ${ }^{12}$ (2006), organizador da obra A ouvidoria brasileira, comemorativa dos dez anos da Associação Brasileira de Ouvidores (ABO), durante a Assembleia Constituinte a proposta de se instituir o ombudsman foi debatida, mas não evoluiu. Por conta do desconhecimento quanto às suas reais atribuições, confundidas, por exemplo, com as funções do Ministério Público, a ideia de sua incorporação à Constituição não vingou e, portanto, não foi incluída no CDC e tampouco no Sistema Nacional de Defesa do Consumidor (SNDC).

Mas, como seus propósitos permaneceram latentes, a instituição da ouvidoria/ombudsman vem se consolidando no âmbito da iniciativa privada e do setor público entre as organizações orientadas por uma conduta diferenciada, que demonstram respeito aos direitos constitucionais do cidadão ao criar um canal direto e privilegiado de comunicação, que informa, responde e encaminha soluções às questões apresentadas.

A ouvidoria tem a importante missão de qualificar as manifestações do consumidor e contribuir para a valorização de suas opiniões no âmbito das organizações públicas e privadas.

Assim, à medida que progride o grau de politização e de conscientização da sociedade com relação aos seus direitos, eleva-se também a frequência da procura aos serviços de atendimento ao consumidor e às ouvidorias como alternativas às quais se pode recorrer em busca de soluções de problemas antes de ir aos tribunais.

\section{Ouvidoria: parte integrante do Sedusp}

O Código de Defesa do Consumidor forneceu a espinha dorsal à lei paulista de defesa do usuário do serviço público. No entanto, se há uma lacuna na lei federal, caracterizada pela ausência da instituição da ouvidoria no SNDC e que não menciona, de forma clara, como deveria estar configurado o serviço advindo da obrigação da empresa de atender o consumidor, tal situação não se repetiu quando da criação do Sistema de Defesa dos Usuários do Serviço Público do Estado de São Paulo (Sedusp), instituído pela Lei n: 10.294, de 20 de abril de 1999, que além de definir as regras, instituiu os elementos essenciais a seu cumprimento.

120 advogado Edson Vismona foi secretário da Justiça e da Defesa da Cidadania do Estado de São Paulo (2000-2002), bem como fundador e presidente da ABO (1997-2005). 
Informação também é seu pilar de sustentação. O artigo $4^{\circ}$ define a informação como o primeiro direito básico do usuário, seguido pelo direito à qualidade na prestação do serviço e pelo direito ao controle adequado do serviço público.

Para assegurar o direito à informação, o artigo seguinte define que o prestador de serviço público é responsável por criar e oferecer ao cidadão as condições adequadas de acesso ao atendimento pessoal e por fornecer informações relativas aos serviços prestados.

Em um paralelo com o Serviço Nacional de Defesa do Consumidor, a lei paulista instituiu o Sistema Estadual de Defesa do Usuário de Serviços Públicos (Sedusp) criado pela legislação paulista, garante, entre outros, o estabelecimento de um canal de comunicação direto entre os prestadores de serviços e os usuários com vistas a contribuir, de modo estratégico, com a melhoria dos serviços e procedimentos do governo do estado de São Paulo. Ele compreende uma rede de ouvidorias ${ }^{13}$, atuando, de forma descentralizada, nos diversos órgãos da administração pública. Existem, atualmente, cerca de duzentas ouvidorias com a incumbência de orientar o usuário, representá-lo e defender seus direitos.

O Sedusp instituiu também a Comissão de Centralização das Informações dos Serviços Públicos do Estado de São Paulo, com a finalidade de sistematizar todas as informações relativas aos serviços especificados nesta lei. Atualmente, tais informações estão disponíveis no portal Cidadão.SP ${ }^{14}$, que, a partir de informações prestadas pelos ouvidores, organiza e atualiza sistematicamente todos os serviços do governo do Estado. Cabe, ainda, à comissão promover a educação do usuário, produzindo manuais informativos dos seus direitos, dos procedimentos disponíveis para o seu exercício e dos órgãos e endereços para apresentação de queixas e sugestões.

Naturalmente, também nesse caso, mesmo que a lei seja impecável, são necessárias, além da vontade política para que os pressupostos se cumpram, tanto a conscientização dos gestores públicos quanto a responsabilidade das instituições como dos usuários sobre seus direitos e conhecimento dos instrumentos disponíveis.

\section{A ouvidoria no sistema financeiro}

A instituição da ouvidoria/ombudsman nas organizações, como presença essencial para garantir o cumprimento da lei e a proteção aos direitos dos consumidores, foi uma vez mais referendada com a criação das ouvidorias nos bancos, por determinação do Banco Central do Brasil.

13 Cf.: <http://www.ouvidoria.sp.gov.br>.

14 Cf.: <http://www.cidadao.sp.gov.br>. 
A despeito de ter sido uma imposição, a Resolução CMN 3.477/2007 $7^{15}$ veio corroborar a necessidade de o cidadão ter acesso a um canal de relacionamento, que opere com autonomia e independência e que possa representar o cidadão com total isenção no interior da instituição financeira para dar seguimento a questões que não foram solucionadas pelos canais convencionais de atendimento.

A resolução preconiza a ampla divulgação sobre a existência da ouvidoria, sua finalidade e forma de utilização, "inclusive por meio dos canais de comunicação utilizados para difundir os produtos e serviços da instituição", o que denota a importância do vínculo estratégico do instituto da ouvidoria com a comunicação organizacional.

\section{CONSIDERAÇÕES FINAIS}

Sem entrar em particularidades da hermenêutica jurídica, a lei que instituiu o Código de Defesa do Consumidor é, em si mesma, reconhecidamente uma virtuose no universo das leis brasileiras. No entanto, é certo que pode ser aprimorada. Como se pode ver, existem aspectos em que poderia ser revista e complementada. No entanto, acreditamos que um dos pontos que pode ser aperfeiçoado é a disseminação da lei e a frequente "tradução" de seu conteúdo.

A relação entre as organizações e os públicos de interesse modificou-se profundamente nos últimos anos. Os consumidores tomaram consciência de seus direitos e passaram a acompanhar mais de perto o desempenho das empresas, exigindo destas mais do que bom desempenho financeiro (BUENO, 2003).

Por conta dessa percepção, tornou-se necessário às organizações coordenar, de modo planejado e sistemático, um conjunto de ações e estratégias, alicerçadas em políticas de relacionamento com seus públicos de interesse e a própria sociedade, de modo geral, uma vez que o alcance de sua reputação depende de diversos públicos, mesmo daqueles com os quais ela não mantém um contato mais estreito. Esses são os princípios básicos da prática da responsabilidade social, alinhados com a prática de relações públicas.

Como alerta James E. Grunig (2009), o termo responsabilidade pública, introduzido por Preston e Post (1975) é mais adequado, pois caracteriza como responsável a organização que assume as consequências que acarreta a seus públicos e pratica com estes a comunicação simétrica ${ }^{16}$ :

Se a comunicação for eficaz, a organização construirá bons relacionamentos. Como resultado, as relações públicas e a responsabilidade pública tornam-se

15 Cf.: <https://www3.bcb.gov.br>.

16 Grunig $(2009$, p. 56) define o modelo simétrico de mão dupla como "o ideal normativo para a prática de relações públicas". 
praticamente sinônimos. Uma organização não pode exercer boas relações públicas sem ser responsável perante seus públicos. (GRUNIG, 2009, p. 33).

Nota-se que teoria e práxis da atividade evoluíram e, hoje, em nada lembram aquele início incidental em que relações públicas serviam para neutralizar o efeito de condutas empresariais danosas, por meio de subterfúgios que as encobrissem e desviassem a atenção da opinião pública apenas para os aspectos positivos das empresas.

A atividade acumulou um passivo mais que suficiente para demonstrar que tem significativa contribuição estratégica a oferecer no contexto das relações das organizações com todos os seus públicos, inclusive usuários e consumidores.

A função social de relações públicas - à qual corresponde o papel educativo atesta a necessária contribuição que esta pode oferecer às empresas, que optam pelo caminho da sustentabilidade, para alcançar seus propósitos de crescimento e desenvolvimento, sem descuidar de sua função social e da governança. Desse modo, especificamente, no âmbito do contexto que norteou a elaboração do presente texto, por melhor que tudo isso esteja traduzido em seus artigos, alíneas e incisos, o CDC sozinho não é capaz de operar as mudanças que dele se espera, pois se trata de um processo que depende do entendimento e da conscientização dos atores nele envolvidos.

As organizações tanto as privadas como as públicas podem e devem adotar estratégias que aprimorem o relacionamento com o consumidor, como o amálgama de sua responsabilidade de proteger e defender os seus direitos. Desse modo, seguem o manual de boas práticas contidos no Código de Defesa do Consumidor e, naturalmente, cumprem a lei.

\section{REFERÊNCIAS}

ALCADE, Tatiana. Novas regras. Consumidor Moderno, São Paulo, Padrão Editorial, a. 13, n. 123, p. 48-50, mar. 2008.

AMARAL, Luiz O. de Oliveira. Relações de consumo. São Paulo: Saraiva, 1991.

ANDRIGHI, Fátima Nancy. 15 anos do Código de Defesa do Consumidor: evoluções processuais e materiais nas relações de consumo - visão crítica do anteprojeto à atualidade. Disponível em: <http://bdjur.stj.jus.br>. Acesso em: fev. 2009.

ANDRADE, Cândido Teobaldo de Souza. Curso de relações públicas: relações com os diferentes públicos. 6. ed. - rev. e ampl. São Paulo, Pioneira Thomson Learning, 2003.

BRASIL. Constituição da República Federativa do Brasil. Disponível em: <https://www.planalto.gov.br>.

BUENO, Wilson da Costa. Comunicação empresarial: teoria e pesquisa. São Paulo: Manole, 2003.

FERRARI, Maria Aparecida. As dimensões locais das relações públicas internacionais: teorias e paradigmas. Organicom - Revista Brasileira de Comunicação Organizacional e Relações Públicas, São Paulo, Gestcorp da ECA-USP / Abrapcorp, a. 3. n. 5, p. 82-95, 2. sem. 2006.

FORNAZARO, Maria Inês. Código de Defesa do Consumidor. São Paulo: Fundação Procon-SP, 1999.

FRANÇA, Fábio. Públicos: como identificá-los em uma nova visão estratégica. São Caetano do Sul, SP: Yendis Editora, 2004. GIACOMINI FILHO, Gino. Consumidor versus propaganda. São Paulo: Summus Editorial, 1991. 
GIANNETTI, Eduardo. Vícios privados, benefícios públicos? : a ética na riqueza das nações. 5. reimpr. São Paulo: Companhia das Letras, 1993.

GRUNIG, James E. Uma teoria geral das relações públicas: quadro teórico para o exercício da profissão. In: GRUNIG, James E.; FERRARI, M. Aparecida; FRANÇA, Fábio. Relações públicas: teoria, contexto e relacionamentos. São Caetano do Sul, SP: Difusão Editora, 2009. p. 15-123.

GRUNIG, James E; HUNT, Todd. Managing public relations. Orlando, CA: Holt, Rinehart and Winston, 1984.

GUAZZELLI, Denize A. Relações públicas e ombudsman: relacionamento 2.0. Anuário Unesco-Metodista de Comunicação Regional, São Bernardo do Campo, Cátedra Unesco-Metodista de Comunicação para o Desenvolvimento Regional, a. 12, n. 12, 2009. p. 159-176.

Estado da arte da comunicação pública. [Resenha do livro Comunicação pública: estado, mercado, sociedade e interesse público - Jorge Duarte (Org.), São Paulo, Atlas, 2007]. Estudos de Jornalismo e Relações Públicas, São Bernardo do Campo, Fajorp-Umesp, a. 5, n. 10, p. 181-183, 2. sem. 2007.

. Relações públicas em defesa do consumidor. Estudos de Jornalismo e Relações Públicas, São Bernardo do Campo, Fajorp-Umesp, a. 2, n 4, p. 52-67, 2. sem. 2004.

Serviço ao consumidor: a experiência brasileira do atendimento on-line. Dissertação (Mestrado em Comunicação Social) - Umesp, 1997.

KUNSCH, Margarida M. Krohling. Planejamento de relações públicas na comunicação integrada. 4. ed. - rev., atual. e ampl. São Paulo: Summus Editorial, 2003

GUERRINI, Estela. Idec considera decreto do SAC positivo, mas balanço de um ano é insatisfatório. 03.12.2009. Disponível em: $<$ http://ultimainstancia.uol.com.br/colunas_ver.php?idConteudo=63542>. Acesso em: mar. 2010.

LAS CASAS, Alexandre Luzzi. Qualidade total em serviços. 5. ed. São Paulo: Atlas, 2006.

MACHADO, Jorge A. S. Ativismo em rede e conexões identitárias: novas perspectivas para os movimentos sociais. Sociologias, Porto Alegre, jul./dez. 2007. Disponível em: <http://www.scielo.br/>. Acesso em: mar. 2009.

MEIR, Roberto. Muito à frente dos americanos. Consumidor Moderno, São Paulo, Padrão Editorial, a. 14, n. 134, p. 12, mar. 2009.

NUNES, Luiz Antonio. Curso prático de direito do consumidor. São Paulo: Revista dos Tribunais, 1992.

OLIVEIRA, José Xavier de. Usos e abusos de relações públicas. Rio de Janeiro: Fundação Getúlio Vargas, 1971.

PRESTON, Lee E.; POST, James E. Private management and public policy. Englewood Cliffs, NJ: Prentice-Hall, Inc., 1975.

SIMÕES, Roberto Porto. Relações públicas: função política. 6. ed. São Paulo: Summus Editorial, 1995.

SROUR, Robert Henry. Ética empresarial. Rio de Janeiro: Campus, 2000.

TASCHNER, Gisela. Cultura, consumo e cidadania. Bauru, SP: Edusc, 2009.

VALENTE, Célia; NORI, Walter. Portas abertas. A experiência da Rhodia: novos caminhos da comunicação social moderna. São Paulo: Best Seller, 1990.

VISMONA, Edson (Org.). A ouvidoria brasileira: dez anos da Associação Brasileira de Ouvidores/Ombudsman. São Paulo: Imprensa Oficial, 2005.

ZÜLZKE, Maria Lúcia. Abrindo a empresa para o consumidor. Rio de Janeiro, Qualitymark Editora, 1990.

Recebido em: 14.02.2010 / Aceito em: 01.04.2010 